\title{
Intramolecular Redox-Active Ligand-to-Substrate Single-Electron Transfer: Radical Reactivity with a Palladium(II) Complex
}

\author{
Daniël L. J. Broere, ${ }^{\dagger}$ Bas de Bruin, ${ }^{\dagger}$ Joost N. H. Reek, ${ }^{\dagger}$ Martin Lutz, ${ }^{\ddagger}$ Sebastian Dechert, ${ }^{\S}$
} and Jarl Ivar van der Vlugt* ${ }^{\dagger}$

${ }^{\dagger}$ Homogeneous, Bioinspired \& Supramolecular Catalysis, van ’t Hoff Institute for Molecular Sciences, University of Amsterdam, Science Park 904, 1098 XH Amsterdam, The Netherlands

${ }^{\ddagger}$ Crystal and Structural Chemistry, Bijvoet Center for Biomolecular Research, Utrecht University, $3584 \mathrm{CH}$ Utrecht, The Netherlands

${ }^{\S}$ Institut für Anorganische Chemie, Georg-August-Universität Göttingen, 37077 Göttingen, Germany

Supporting Information

ABSTRACT: Coordination of the redox-active tridentate NNO ligand $\mathrm{L}^{\mathrm{H} 2}$ to $\mathrm{Pd}^{\mathrm{II}}$ yields the paramagnetic iminobenzosemiquinonato complex 3. Single-electron reduction of 3 yields diamagnetic amidophenolato complex 4, capable of activating aliphatic azide $\mathbf{5}$. Experimental and computational studies suggest a redoxnoninnocent pathway wherein the redox-active ligand facilitates intramolecular ligand-to-substrate single-electron transfer to generate an open-shell singlet "nitrene-substrate radical, ligand radical”, enabling subsequent radical-type $\mathrm{C}-\mathrm{H}$ amination reactivity with $\mathrm{Pd}^{\mathrm{II}}$.

R edox-active ligands are highly relevant for many metalRloenzymatic transformations, supplying electrons and facilitating selective atom transfer reactivity. ${ }^{1}$ Synthetic analogues have recently also shown remarkable potential in enabling two-electron redox processes for bond activation and formation processes, either acting as an electron reservoir or directing radical-type reactivity when combined with transition metals. ${ }^{2}$ Single-electron transfer (SET) from a redox-active ligand to a substrate without metal oxidation state change is very rare. $^{3}$ Transformations mediated by palladium are dominated by two-electron processes, ${ }^{4}$ whereas ligand-tosubstrate SET might allow selective substrate activation via a controlled radical-type mechanism while benefiting from favorable Pd-substrate coordination.

In order to induce and control this ligand-to-substrate electron transfer reactivity on a suitable stable Pd platform and to avoid ligand dissociation during the redox-state shuttling events, we integrated the redox-active 2-aminophenol ${ }^{5}\left(N^{\mathrm{H}} \mathrm{O}^{\mathrm{H}}\right)$ unit within a tridentate $\mathrm{NN}^{\mathrm{H}} \mathrm{O}^{\mathrm{H}}$ pincer ${ }^{6}$ scaffold. Upon double deprotonation, this ligand may coordinate to $\mathrm{Pd}^{\mathrm{II}}$ as a 2amidophenolato dianion $\left(\mathrm{NNO}{ }^{\mathrm{AP}}\right)$, iminobenzosemiquinonato radical monoanion $\left(\mathrm{NNO}{ }^{\mathrm{ISQ}}\right)$, or a neutral iminobenzoquinone $\left(\mathrm{NNO}^{\mathrm{IBQ}}\right.$, Figure 1), without formal redox changes occurring at $\mathrm{Pd}^{7}$ Single-electron transfer reactivity from such an NOfragment to exogenous electron acceptors is not described to date for any of its redox states. We envisioned that the $\left(\mathrm{NNO}^{\mathrm{AP}}\right)$ state might be ideally suited to establish intramolecular ligand-to-substrate electron shuttling and to perform radical-type reactions with $\mathrm{Pd}^{\mathrm{II}}$.
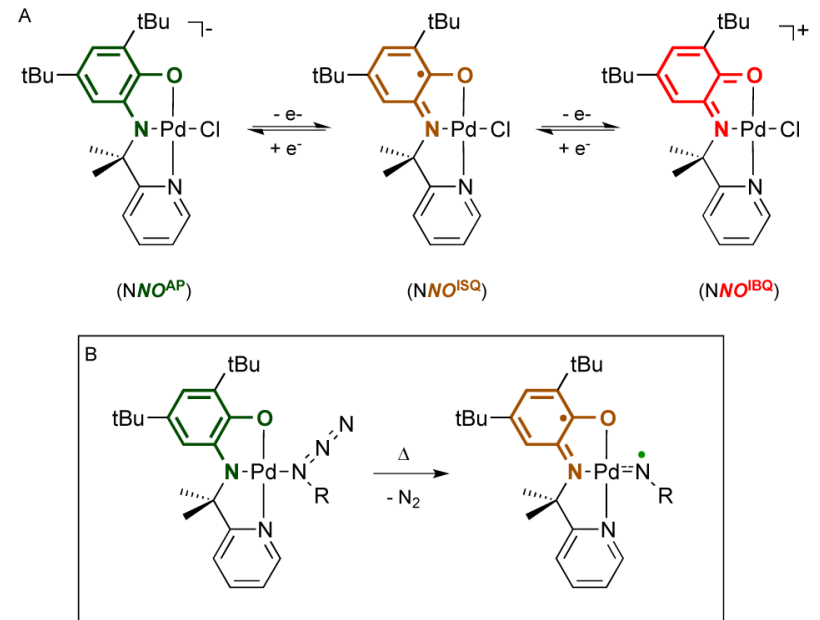

Figure 1. (A) Redox states of $\mathrm{Pd}^{\mathrm{II}}$-coordinated NNO ligand. (B) Concept of ligand-to-substrate single-electron transfer demonstrated for an azide substrate, generating a "nitrene-substrate radical, ligand radical" on $\mathrm{Pd}^{\mathrm{II}}$.

We herein report the synthesis of this new redox-active $\mathrm{N} N^{\mathrm{H}} \mathrm{O}^{\mathrm{H}}$ pincer ligand, bearing an additional pyridine donor to impart coordinative stability, the resulting air- and moisturestable paramagnetic $\mathrm{Pd}^{\mathrm{II}}$ complex $(S=1 / 2) 3$, and its oneelectron reduced diamagnetic derivative 4 . The ligand-centered redox behavior of this one-electron reduced species was probed experimentally and computationally (DFT). The combined data indicate that single-electron transfer from the redox-active ligand to an organic azide occurs under thermal activation to produce a "nitrene-substrate radical, ligand-radical" $\mathrm{Pd}^{\mathrm{II}}$ intermediate with an open-shell singlet (singlet diradical) ground state. As proof-of-principle reactivity with this ligandbased electron transfer concept, this unusual intermediate undergoes intramolecular $s p^{3} \mathrm{C}-\mathrm{H}$ amination to generate a pyrrolidine species.

The two-step synthesis of $\mathrm{NN}^{\mathrm{H}} \mathrm{O}^{\mathrm{H}}$ ligand $\mathbf{L}^{\mathrm{H} 2}$ involves double addition of $\mathrm{MeCeCl}_{2}$ on 2-cyanopyridine ${ }^{8}$ to form amine 1 (Scheme 1), followed by condensation with 1,3-di(tert-

Received: March 3, 2014

Published: June 13, 2014 
Scheme 1. Synthesis of $\mathrm{L}^{\mathrm{H} 2}, 2,3$, and $4^{a}$

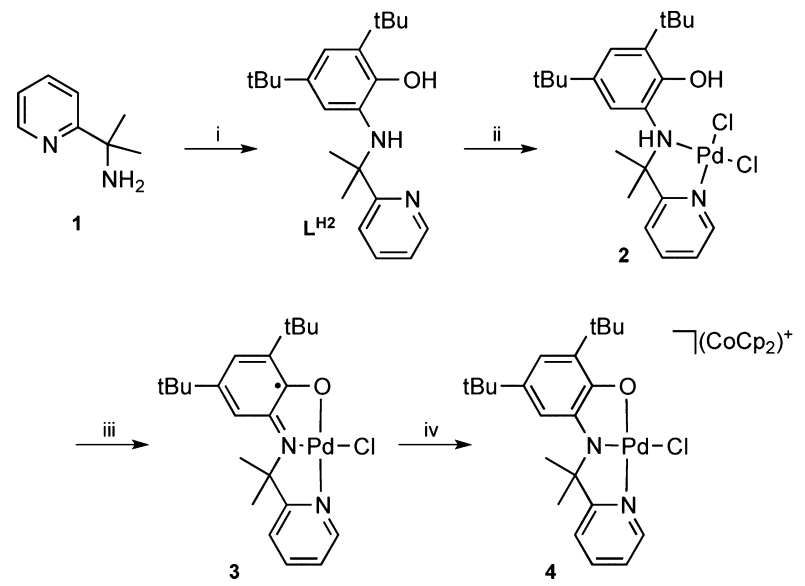

${ }^{a}$ Reagents: (i) DTBQ DTBC, neat; (ii) $\mathrm{PdCl}_{2}(\mathrm{NCMe})_{2}$; (iii) $\mathrm{NEt}_{3}$, air; (iv) $\mathrm{CoCp}_{2}$.

butyl)quinone to produce an iminoquinone intermediate that is reduced in situ by 1,3-di(tert-butyl)catechol. ${ }^{9}$ The geminal methyl and tert-butyl groups are incorporated in the framework to prevent $\beta-\mathrm{H}$ elimination and to stabilize the $N N O^{\mathrm{ISQ}}$ oxidation state upon coordination, respectively. Colorless solid $\mathbf{L}^{\mathbf{H 2}}$ is bench-stable for months but susceptible to oxidation in solution under air, concomitant with a color change to green and broadening of the NMR signals. For reference, we also synthesized $\mathbf{L}^{\prime H 2}$ bearing no gem-dimethyl groups. $^{10}$

Ligand $\mathrm{L}^{\mathrm{H} 2}$ reacts as a neutral ligand with $\mathrm{PdCl}_{2}(\mathrm{MeCN})_{2}$ to give orange $\mathrm{PdCl}_{2}\left(\mathrm{~L}^{\mathrm{H} 2}\right)$ (2) in high yield. $\mathrm{NMR}$ analysis suggests pyridine and $-\mathrm{NH}$ coordination to $\mathrm{Pd}$ (diastereotopic $-\mathrm{CH}_{3}$ groups; $\delta 6.58(\mathrm{NH})$ ), with no interaction of the $-\mathrm{OH}$ group $(\delta 6.53) .{ }^{10}$ Addition of $\mathrm{NEt}_{3}$ in $\mathrm{MeOH}$ under aerobic conditions resulted in brown paramagnetic compound 3, characterized as $\operatorname{PdCl}\left(\mathbf{L}^{\bullet}\right)\left(\mathbf{L}^{\bullet}=N N O^{\mathrm{ISQ}}\right)$. Magnetic susceptibility measurement of 3 at $298 \mathrm{~K}$ using Evans' method $^{11}$ gave an effective magnetic moment $\left(\mu_{\text {eff }}\right)$ of 1.78 $\mu_{\mathrm{B}}$, indicating an $S=1 / 2$ ground state. X-band EPR spectroscopy in toluene at $298 \mathrm{~K}$ (Figure 2, left) revealed hyperfine couplings with ${ }^{105} \mathrm{Pd},{ }^{15} \mathrm{~N}$, and two ${ }^{1} \mathrm{H}$ nuclei. The simulated spectrum and calculated hyperfine couplings
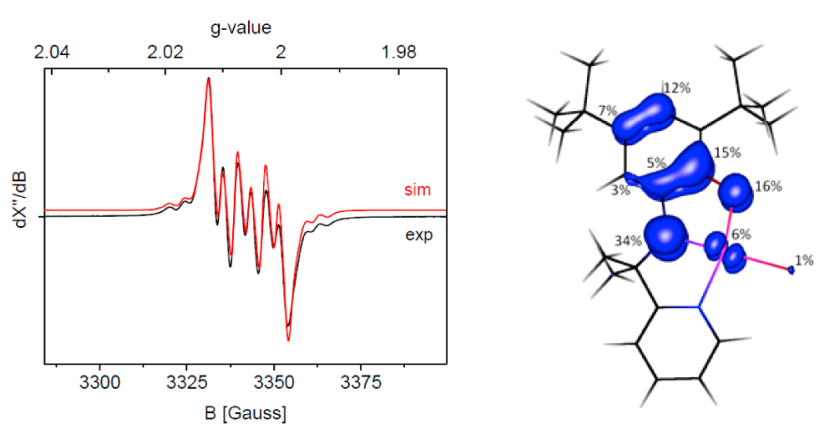

Figure 2. Left: Experimental and simulated EPR spectrum of 3 . Microwave frequency $=9.382892 \mathrm{GHz}$. Power $=2 \mathrm{~mW}$. Modulation amplitude $=0.1 \mathrm{G}$. Simulated $(\mathrm{DFT}) \mathrm{g}$ value and hyperfine couplings $A(\mathrm{MHz}): g_{\text {iso }} 2.0055(2.0059) ; A^{\mathrm{Pd}}$ iso $+12.8(+10.7) ; A^{\mathrm{N}}$ iso +22.8 $(+17.1) ; A^{\mathrm{H} 1}$ iso $-10.6(-7.9) ; A^{\mathrm{H} 2}$ iso $-2.8(-2.4)$. DFT parameters: ORCA (b3-lyp/def2-TZVP). Right: DFT (b3-lyp/def2-TZVP) calculated spin-density plot for 3 . correlate well with the experimental data. The $g_{\text {iso }}$ value of 2.0055 supports an $N N O^{\mathrm{ISQ}}$ ligand radical coordinated to $\mathrm{Pd}^{\mathrm{II}}$. The calculated spin-density plot for 3 ( $93 \%$ total spin density, $34 \%$ on the iminosemiquinonato nitrogen) is in agreement with EPR data (Figure 2, right).

The molecular structure of 3 (Figure 3) shows metric parameters that are characteristic for the $(N) N O^{I S Q}$ ligand
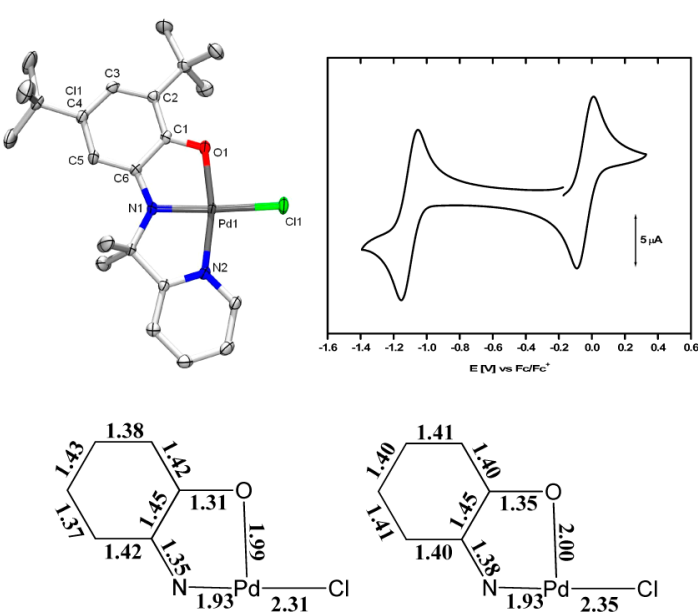

Figure 3. Top left: Displacement ellipsoid plot (50\% probability level) of $3 . \mathrm{H}$ atoms and solvent omitted for clarity. ${ }^{11}$ Top right: Cyclic voltammogram of 3 in $\mathrm{CH}_{2} \mathrm{Cl}_{2}\left(10^{-3} \mathrm{M}\right)$; scan rate $200 \mathrm{mV} \mathrm{s}{ }^{-1}$; referenced to $\mathrm{Fc} / \mathrm{Fc}^{+}$. Bottom: Relevant XRD metric parameters of 3 (left) and 4 (right).

oxidation state. ${ }^{12}$ DFT (b3-lyp/def2-TZVP) calculated optimized geometric parameters for the doublet $N N O^{\mathrm{ISQ}}$ ground state matched well with the experimentally found values. ${ }^{10}$ Cyclic voltammetry of 3 in $\mathrm{CH}_{2} \mathrm{Cl}_{2}$ solution revealed fully reversible one-electron oxidation and reduction events at +0.04 $\mathrm{V}$ and $-1.11 \mathrm{~V}$ vs $\mathrm{Fc} / \mathrm{Fc}^{+}$, respectively (Figure 3, right). Chemical reduction of 3 with $\mathrm{CoCp}_{2}$ in $\mathrm{CH}_{2} \mathrm{Cl}_{2}$ furnished $\left[\mathrm{CoCp}_{2}\right]\left[\mathrm{PdCl}\left(\mathrm{NNO}^{\mathrm{AP}}\right)\right]$ as soluble, air-sensitive diamagnetic species 4 . Single crystals were obtained by reactive diffusion of a CoCp $\mathrm{p}_{2}$ solution into a solution of 3 in benzene. The anionic portion of this complex is almost isostructural to 3 (Figure 3 ), showing an elongated $\mathrm{Pd}-\mathrm{Cl}$ bond and characteristic bond lengths for the $(N) N O^{\mathrm{AP}}$ oxidation state that matched well with DFT calculated metric parameters. Synthesis of the neutral analogue $4 \mathrm{PPh}_{3}$ was achieved by addition of 1 equiv of $\mathrm{PPh}_{3}$ to either the in situ reduction of 3 or preformed $4 .^{10}$

We anticipated that the reduced nature of the $N N O^{\mathrm{AP}}$ scaffold in species 4 could be utilized to generate an unpaired electron at a coordinated substrate by unprecedented intramolecular ligand-to-substrate SET on $\mathrm{Pd}^{\mathrm{II}}$. To support this hypothesis, we performed DFT calculations on 4 with model azide $\mathbf{N}_{3}{ }^{\text {Et }}$. MO plot analysis showed that loss of $\mathrm{N}_{2}$ concomitant with SET from the $N N O^{\mathrm{AP}}$ ligand to the nitrene substrate is indeed accessible, generating a rare "nitrenesubstrate radical, ${ }^{13,14}$ ligand-radical" $\mathrm{Pd}^{\mathrm{II}}$ species $5 \mathrm{~N}^{\mathrm{R}}$ with an open-shell singlet (singlet diradical) ground state. $5 \mathrm{~N}^{\mathrm{R}}$ bears $87 \% \alpha$-spin density at the nitrene $\mathrm{N}$-atom (Figure 4; left: HOMO for $4 \mathbf{N}_{3}{ }^{\mathbf{R}}$, right: spin density distribution for $5 \mathrm{~N}^{\mathrm{R}}$ ).

To exploit this concept of ligand-based single-electron transfer to generate a substrate radical, we investigated the reactivity of these $\mathrm{Pd}(\mathrm{NNO})$ complexes in radical-type $s p^{3} \mathrm{C}-$ $\mathrm{H}$ amination. ${ }^{15}$ These reactions often proceed via a radical-type mechanism involving $\mathrm{C}-\mathrm{H}$ abstraction followed by a radical- 


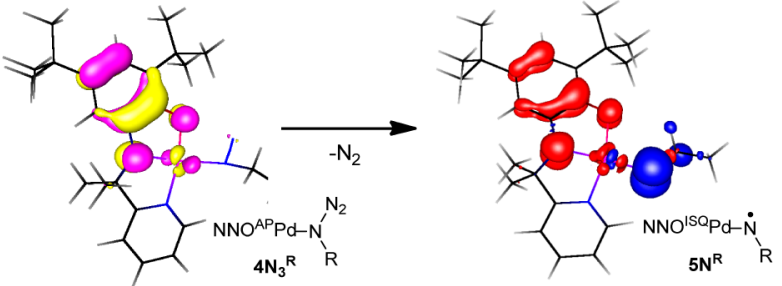

Figure 4. DFT (b3-lyp/def2-TZVP) calculated HOMO plot for model complex $4 \mathbf{N}_{3}{ }^{\mathrm{R}}$ (left) and spin-density plot for model diradical $5 \mathbf{N}^{\mathrm{R}}$ (right) with blue: positive $(\alpha)$ and red: negative $(\beta)$ spin density. $\mathbf{R}=$ ethyl.

rebound step, or alternatively via direct insertion of the radical nitrene fragment in the $\mathrm{C}-\mathrm{H}$ bond. The Fe-mediated $\mathrm{C}-\mathrm{H}$ amination of unactivated alkyl azides occurs via a radical pathway involving metal-based redox chemistry, ${ }^{16}$ but a ligandinduced radical pathway for this reaction has never been disclosed. Upon reduction of 3 to 4 with cobaltocene in the presence of unactivated azide 5 and $\mathrm{Boc}_{2} \mathrm{O}$, pyrrolidine $6(\sim 1$ equiv with respect to 4 ), and the reduced Boc-protected amine 7 were observed (Scheme 2). Use of $4 \mathbf{P P h}_{3}, \mathrm{Pd}_{2}^{0}(\mathrm{dba})_{3}$,

Scheme 2. Conversion of Azide 5 into Pyrrolidine 6

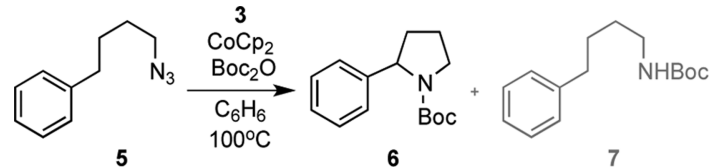

$\mathrm{Pd}^{\mathrm{II}} \mathrm{Cl}_{2}(\mathrm{NCMe})_{2}$, complex 2 (with and without $\mathrm{CoCp}_{2}$ ), complex 3 (with and without $\mathrm{AgPF}_{6}$ or $\mathrm{TlPF}_{6}$ ), $\mathrm{CoCp}_{2}$, or $\mathrm{CoCp}_{2}{ }^{+}$did not result in the formation of product $6 .{ }^{17}$ The analogous PdCl-complex of $\mathbf{L}^{\prime H 2}$ was inactive, likely due to formation of iminopyridyl ligand $\mathrm{L}^{\prime \mathrm{H}}$ via facile $\beta$-H elimination, which prohibits redox activity of the NO-fragment. Notably, in the presence of TEMPO-H, reaction of in situ generated 4 with azide 5 did not lead to any pyrrolidine formation, and the detection of TEMPO ${ }^{\bullet}$ by EPR spectroscopy ${ }^{10}$ supports the trapping of an active radical intermediate.

Based on these data and supported by DFT calculations, we propose the following mechanism for the intramolecular cyclization using 4 (Scheme 3). Initial chloride substitution by azide $\mathbf{5}$ gives closed-shell singlet (CSS) species $\mathbf{A}$ with an

Scheme 3. OSS Pathway from Azide 5 into 6 via RadicalType $s p^{3} \mathrm{C}-\mathrm{H}$ Amination with 4; calculated free energies $\Delta G$ for species A-D and transition states (red) and relative barriers $\Delta \Delta G$ (blue) in kcal $\mathrm{mol}^{-1}$

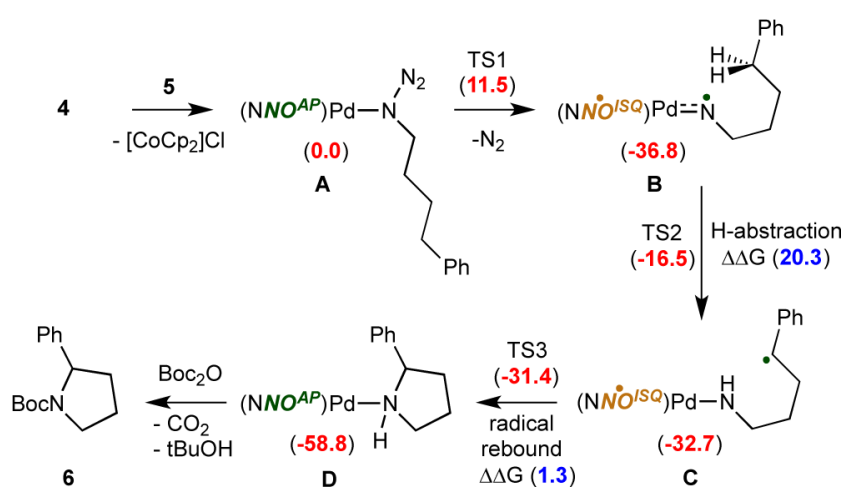

$\mathrm{NNO}^{\mathrm{AP}}$ ligand. Loss of $\mathrm{N}_{2}$ generates Pd-nitrene intermediate $\mathbf{B}$ that can exist in three plausible electronic states. The open-shell singlet diradical (OSS) is more stable than the CSS and triplet states by 10.6 and $5.8 \mathrm{kcal} / \mathrm{mol}$, respectively. Furthermore, the OSS nitrene diradical $\mathbf{B}$ is most effectively generated from $\mathbf{A}$ (lowest barrier of $11.5 \mathrm{kcal} \mathrm{mol}^{-1}$ ) via electron transfer from the NNO-ligand, with no redox chemistry occurring at Pd. Subsequent intramolecular $\mathrm{H}$-atom abstraction forms intermediate C for the OSS and triplet states with barriers of 20.3 and $19.4 \mathrm{kcal} \mathrm{mol}^{-1}$, respectively. A subsequent low barrier transition state for the radical rebound step $\left(1.3 \mathrm{kcal} \mathrm{mol}^{-1}\right)$ to form $\mathbf{D}$ was found on the OSS surface. For the CSS species, direct $\mathrm{C}-\mathrm{H}$ insertion of the nitrene fragment in $\mathbf{B}$ to form $\mathbf{D}$ has a higher absolute barrier than the stepwise radical process on the OSS surface (Figure 5). Reaction of intermediate $\mathbf{D}$ with

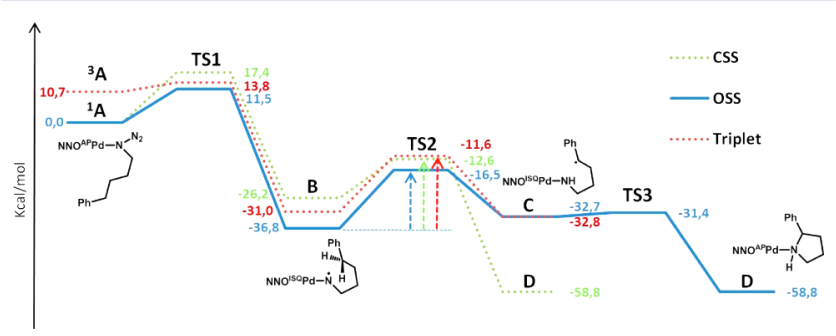

Figure 5. DFT (b3-lyp/def2-TZVP) calculated free energy profile $\Delta G^{\circ}{ }_{298 \mathrm{~K}}\left(\right.$ in $\mathrm{kcal} \mathrm{mol}^{-1}$ ) for $\mathrm{C}-\mathrm{H}$ amination of azide complex $\mathbf{A}$ derived from 4 for the three possible spin states.

$\mathrm{Boc}_{2} \mathrm{O}$ gives 6 and an unidentified paramagnetic Pd complex. Reaction of independently prepared $\mathbf{D}$, by addition of pyrrolidine to 4, with $\mathrm{Boc}_{2} \mathrm{O}$ also generated product 6 . Using an isotopically labeled analogue of azide 5, selectively monodeuterated at the benzylic position, ${ }^{10}$ we established a kinetic isotope effect (KIE) of $3.35 \pm 0.1$ for formation of 6 , which is reproduced very well by DFT calculations (KIE of 3.65). Attempts to trap a rare $\mathrm{Pd}$ (organo-azide) complex or a hitherto elusive (quasi)stable Pd-nitrene analogue of $\mathbf{B}$ using e.g. $\mathrm{PhI}=\mathrm{NNs}, \mathrm{AdN}_{3}$, or $\mathrm{C}_{6} \mathrm{~F}_{5} \mathrm{~N}_{3}$ did not provide a clear indication for the formation of such species. ${ }^{10}$

In conclusion, a new redox-active NNO pincer ligand $\mathrm{L}^{\mathrm{H} 2}$ has been synthesized and coordinated to $\mathrm{Pd}^{\mathrm{II}}$, affording paramagnetic $(S=1 / 2)$ complex 3 bearing the ligand-centered radical $\mathrm{NNO}^{\mathrm{ISQ}}\left(\mathrm{L}^{\bullet}\right)$, as supported by spectroscopic, X-ray crystallographic, and computational data. Reduction of 3 generates diamagnetic complex 4, $[\mathrm{CoCp} 2]\left[\mathrm{PdCl}\left(\mathrm{NNO}^{\mathrm{AP}}\right)\right]$, which is able to activate azide 5 for intramolecular $\mathrm{C}-\mathrm{H}$ bond amination to produce pyrrolidine 6 . DFT calculations, isotopic labeling, and trapping experiments support a process that involves intramolecular single-electron transfer from the redoxactive ligand to the substrate upon thermal activation of the organic azide, thus producing an unusual 'nitrene-substrate radical, ligand-radical' $\mathrm{Pd}^{\mathrm{II}}$ intermediate $\mathbf{B}$ with an open-shell singlet (singlet diradical) ground state. The noninnocent NNO ligand is proposed to dictate single-electron reactivity onto $\mathrm{Pd}^{\mathrm{II}}$, enabling radical-type pathways using a metal that is normally involved in two-electron processes. This concept is likely more broadly applicable with group 8-10 metals, including for cooperative bond activation processes and catalysis. 


\section{ASSOCIATED CONTENT}

\section{(S Supporting Information}

General methods, experimental data for new compounds, NMR spectra, crystallographic details and cif files for 3 and $\mathbf{4}$, computational data. This material is available free of charge via the Internet at http://pubs.acs.org.

\section{AUTHOR INFORMATION}

\section{Corresponding Author}

j.i.vandervlugt@uva.nl

\section{Notes}

The authors declare no competing financial interest.

\section{ACKNOWLEDGMENTS}

Research funded by the European Research Council (ERC Starting Grant 279097 to J.I.v.d.V.). NWO is thanked for financing the X-ray diffractometer at UU. We thank Prof. Franc Meyer (Göttingen) for access to his XRD equipment.

\section{REFERENCES}

(1) (a) Stubbe, J.; van der Donk, W. A. Chem. Rev. 1998, 98, 705. (b) Harris, D. L. Curr. Opin. Chem. Biol. 2001, 5, 724. (c) Que, L.; Tolman, W. B. Nature 2008, 455, 333. (d) Kaim, W.; Schwederski, B. Coord. Chem. Rev. 2010, 254, 1580.

(2) (a) van der Vlugt, J. I. Eur. J. Inorg. Chem. 2012, 363. (b) Lyaskovskyy, V.; de Bruin, B. ACS Catal. 2012, 2, 270. (c) Dzik, W. I.; van der Vlugt, J. I.; Reek, J. N. H.; de Bruin, B. Angew. Chem., Int. Ed. 2011, 50, 3356. (d) Kaim, W. Inorg. Chem. 2011, 50, 9752. (e) Chirik, P. J.; Wieghardt, K. Science 2010, 327, 794. (f) Wong, J. L.; Sánchez, R. H.; Logan, J. C.; Zarkesh, R. A.; Ziller, J. W.; Heyduk, A. F. Chem. Sci. 2013, 4, 1906. (g) Myers, T. W.; Berben, L. A. Chem. Commun. 2013, 49, 4175. (h) Smith, A. L.; Hardcastle, K. I.; Soper, J. D. J. Am. Chem. Soc. 2010, 132, 14358. (i) Sylvester, K. J.; Chirik, P. J. J. Am. Chem. Soc. 2009, 131, 8772. (j) Königsmann, M.; Donati, N.; Stein, D.; Schönberg, H.; Harmer, J.; Sreekanth, A.; Grützmacher, H. Angew. Chem., Int. Ed. 2007, 46, 3567.

(3) Lippert, C. A.; Arnstein, S. A.; Sherill, C. D.; Soper, J. D. J. Am. Chem. Soc. 2010, 132, 3879. See also ref $2 b$ and i.

(4) Mono- and dinuclear Pd ${ }^{\mathrm{III}}$ open-shell species: (a) Mazzotti, A. R.; Cambell, M. G.; Tang, P.; Murphy, J. M.; Ritter, T. J. Am. Chem. Soc. 2013, 135, 14012. (b) Powers, D. C.; Ritter, T. Top. Organomet. Chem. 2011, 503, 129. (c) Boisvert, L.; Denney, M. C.; Hanson, S. K.; Goldberg, K. I. J. Am. Chem. Soc. 2009, 131, 15802.

(5) (a) Min, K. S.; Weyhermüller, T.; Bothe, E.; Wieghardt, K. Inorg. Chem. 2004, 43, 2922. (b) Ringenberg, M. R.; Kokatam, S. L.; Heiden, Z. M.; Rauchfuss, T. B. J. Am. Chem. Soc. 2008, 130, 788. (c) Deibel, N.; Schweinfurth, D.; Hohloch, S.; Delor, M.; Sazanovich, I. V.; Towrie, M.; Weinstein, J. A.; Sarkar, B. Inorg. Chem. 2014, 53, 1021.

(6) (a) van Koten, G.; Milstein, D. Organometallic Pincer Chemistry; Springer: Heidelberg, 2012. (b) Gunanathan, C.; Milstein, D. Acc. Chem. Res. 2011, 44, 588. (c) van der Vlugt, J. I.; Reek, J. N. H. Angew. Chem., Int. Ed. 2009, 48, 8832. $\mathrm{Pd}$ (pyridyl-based pincer) species: (d) Feller, M.; Ben-Ari, E.; Iron, M. A.; Diskin-Posner, Y.; Leitus, G.; Shimon, L. J. W.; Konstantinovski, L.; Milstein, D. Inorg. Chem. 2010, 49, 1615. (e) van der Vlugt, J. I.; Siegler, M. A.; Janssen, M.; Vogt, D.; Spek, A. L. Organometallics 2009, 28, 7025. (f) Gómez-Blanco, N.; Fernández, J. J.; Fernández, A.; Vázquez-García, D.; López-Torres, M.; Vila, J. M. Eur. J. Inorg. Chem. 2009, 3071. (g) Michael, F. E.; Cochran, B. M. J. Am. Chem. Soc. 2006, 128, 4246.

(7) $\mathrm{Pd}^{\mathrm{II}}$ complexes based on 2-aminophenol: (a) Kokatam, S.-L.; Chaudhuri, P.; Weyhermüller, T.; Wieghardt, K. Dalton Trans. 2007, 373. (b) Kokatam, S.; Weyhermüller, T.; Bothe, E.; Chaudhuri, P.; Wieghardt, K. Inorg. Chem. 2005, 44, 3709.

(8) Ciganek, E. J. Org. Chem. 1992, 57, 4521.
(9) Adapted from: Bang, Z. N.; Komissarov, V. N.; Sayapin, Y. A.; Tkachev, V. V.; Shilov, G. V.; Aldoshin, S. M.; Minkin, V. I. Russ. J. Org. Chem. 2009, 45, 442.

(10) See Supporting Information for details.

(11) Sur, S. K. J. Magn. Reson. 1989, 82, 169.

(12) (a) Lippert, C.; Hardcastle, K. I.; Soper, J. D. Inorg. Chem. 2011, 50, 9864. (b) Sun, X.; Chun, H.; Hildenbrand, K.; Bothe, E.; Weyhermüller, T.; Neese, F.; Wieghardt, K. Inorg. Chem. 2002, 41, 4295. (c) Chaudhuri, P.; Verani, C. N.; Bill, E.; Bothe, E.; Weyhermüller, T.; Wieghardt, K. J. Am. Chem. Soc. 2001, 123, 2213.

(13) Review, $N$-centered ligand radicals in catalysis: (a) Olivos Suárez, A. I.; Lyaskovskyy, V.; Reek, J. N. H.; van der Vlugt, J. I.; de Bruin, B. Angew. Chem., Int. Ed. 2013, 52, 12510. See also: (b) Lyaskovskyy, V.; Olivos Suárez, A. I.; Lu, H.; Jiang, H.; Zhang, X. P.; de Bruin, B. J. Am. Chem. Soc. 2011, 133, 12264. Proposed Pdnitrene or -imido species: (c) Mooibroek, T. J.; Schoon, L.; Bouwman, E.; Drent, E. Chem.-Eur. J. 2011, 17, 13318. (d) Berry, J. F. Comm. Inorg. Chem. 2009, 30, 28.

(14) $\mathrm{Pd}$ (organo-azide) complexes are very rare: (a) Barz, M.; Herdtweck, E.; Thiel, W. Angew. Chem., Int. Ed. 1998, 37, 2262. (b) Besenyei, G.; Párkányi, L.; Foch, I.; Simándi, L. I. Angew. Chem., Int. Ed. 2000, 39, 956.

(15) Reviews: (a) Jeffrey, J. L.; Sarpong, R. Chem. Sci. 2013, 4, 4092. (b) Roizen, J. L.; Harvey, M. E.; Du Bois, J. Acc. Chem. Res. 2012, 45, 911. (c) Gephart, R. T.; Warren, T. H. Organometallics 2012, 31, 7727.

(16) Hennessy, E. T.; Betley, T. A. Science 2013, 340, 591.

(17) $\mathrm{Pd}_{2} \mathrm{dba}_{3}$ did lead to full conversion, but only to 7. Pd-black is observed after reaction; we propose that a decomposition product of 4 is responsible for the formation of 7 . 